EPiC Series in Education Science
Volume 3, 2020, Pages 152-161
Proceedings of the MIT LINC 2019 Conference

\title{
Challenges and Impact of Teaching English in Limited Access to Technology Environment
}

\author{
Merita Hoxha ${ }^{1}$, Vilma Tafani ${ }^{2}$ and Keith Kennetz ${ }^{3}$ \\ University of Elbasan “Aleksander Xhuvani”, Albania \\ hoxha.merita@yahoo.com \\ University of Elbasan “Aleksander Xhuvani”, Albania \\ vilmatafaniegmail.com \\ English Language Fellow \\ k kennetz@hotmail.com
}

\begin{abstract}
Technology surrounds us everywhere, every moment. It seems almost impossible to imagine our life without technology, but in fact there are places and people who have little in the way of technological resources. This is the case for 47 underprivileged young learners (third graders) in the city of Elbasan, Albania. These third graders are part of a project which aims at enhancing their English with the aid of 12 pre-service teachers of English, through fun activities, games and use of technology. In a time when technology has become a common educational tool in many developed countries, these third graders have very limited technology access both at home and at schools. They live in the "Global Village" and should be well prepared to participate in it. For this reason, the project is trying to give these students as much access to technology in the classroom as possible to make learning English fun, and at the same time researching how would the use of technology influence their learning. This paper tries to answer the following research questions: 1. How does the use of technology influence the English language learning? 2. What are some of the challenges that pre-service teachers face while teaching in a low tech class? To answer these research questions observation and interviews were conducted. The observations were carried out from November 2018-January 2019 and the interviews in January 2019. The results indicate that third graders are more enthusiastic and engaged in learning during classes when the activities include the use of technology. The pre-service teachers faced various challenges when using technology in class such as the lack of tech equipment, not being able to observe
\end{abstract}


many activities which integrate technology in class and the lack of experience of employing tech equipment. When available both third graders and pre-service teachers embraced the use of technology as a tool to make teaching and learning English fun and inclusive.

Key words: limited technology, pre-service teachers, third graders, Albanian schools

\section{Introduction}

\subsection{Context}

For many years, Albanian teachers of languages relied mostly on traditional teaching methods, especially Grammar Translation (GT) and because of this, little attention was paid to speaking, communication, group work and alternative approaches. After the 90's the aim of the National Curricula for Language learning shifted from GT to Communicative Language Teaching (CLT) methods. Textbooks were changed, new methods were introduced and more attention was given to speaking and reading. The student centered approach was introduced and many visionary teachers embraced it. Today more and more language teachers in Albania are using CLT methods and student centered approaches. They focus on project-based learning, collaboration, creative and critical thinking strategies, and group work.

In 2015 the Ministry of Education in Albania started to implement a new curriculum: the Competence-Based Curriculum which aims at making K-12 students competent in seven different fields: 1. Communication competence, 2. Thinking competence 3. Learning to learn competence 4. Life, enterprise and environment competence 5. Personal competence 6. Social competence and 7. Digital competence. If we judge from the paper's aims or viewpoints we understand that the 7 competences of the Competence-Based Curriculum are closely related to learning English through collaboration, fun activities, and games and technology. The government initiative is well-meaning but it has become very challenging for both teachers and students considering that many schools cannot provide the technology to help in acquiring these competences.

Many schools in major cities are equipped with computer labs, photocopy machines, video projectors and other technology devices; however, in other schools the situation is different. Devices might not be in good working condition and there might not be any internet connection. The situation becomes worse if we consider that many schools rely on contributions from the community or nonprofit organizations to provide paper and ink for the printer, the photocopy machine. Many teachers in these schools have to bring their own technological devices to work such as their phones and speakers in order to practice activities which require the use of technology.

Despite these obstacles, technology is an important tool which is helping in-service and preservice teachers prepare engaging activities, apply CLT methods, make language learning enjoyable and exciting. The pre-service teachers involved in this study's project were continuously tasked to include technology as a learning tool in their English lessons so that their students would be exposed to new activities and teaching methods. 


\subsection{Project}

Being experienced in pre-service teacher training the researchers identified areas where they should focus more on the preparation of future teachers of English and continuously work with national and international partners in order to bring about significant changes. Part of this strategy is the implementation of the project "Teaching English to Underprivileged Young Learners", which aims at giving preservice teachers a hands-on experience in teaching English, while also focusing on integrating the use of technology in the classroom. The project primarily aims at assisting in giving pre-service teachers an opportunity to develop their language and teaching skills. At the same time, the project gives supplementary English lessons to the third graders through fun activities, games and the use of technology considering that almost all these students have very limited access to technology at home. For this reason, the pre-service teachers were asked to include the use of technology in almost every class they had to teach.

During 2018-2019 two university teachers and one English Language Fellow allocated at Aleksander Xhuvani University in Elbasan, Albania, created and carried out the project "Teaching English to Underprivileged Young Learners", which was funded by the U.S. Embassy in Tirana. 12 preservice teachers studying at Aleksander Xhuvani University were selected to give lessons to 47 underprivileged students of the third grade in two elementary schools in Elbasan. The selection of the third graders taking part of the project was done after a considerable field work in cooperation with the Department of Education in Elbasan. Most of the third graders belong to Roma and Egyptian communities and also to families with disadvantaged social and economic backgrounds. Three third graders are children with special needs.

\section{Literature Review}

The use of technology is considered a right and a must in most developed countries and Hamilton (2015) supports this idea by introducing 8 premises: when students use technology, they talk (premise 2), students learn when they actively participate (premise 3), students have a right to use technology in every class, every year (premise 5) and everything is easier with a partner (premise 7).

More and more research emphasizes the benefits of using technology as a tool in the field of education. It is supposed to enrich English language classroom, supporting student-centered methodologies, students' thinking skills and motivation as well. Qoitassi \& Sharif (2015) claim that technology plays a very important role in English teaching and using multimedia to create a context to teach English has its unique advantages. Peters (2009) says that instead of learning about the world in the abstract, students now have the opportunity to experience the world firsthand through the power of the Internet. Wenglinsky (2005) thinks that integrating technology in the classroom is beneficial not only for the learners but also for the teachers. The author claims that computers have not replaced teachers, but instead have given them an opportunity to be more productive. So important is the use of technology in the field of education that Wenglinsky (2005) mentions three movements of improving schools: the standards movement, the technology movement, and the movement to improve teacher quality explaining that the core of the technology movement is that technology could be a crucial tool in helping students meet higher standards. Technology tools add value to learning about complex ideas and difficult subject matter and they foster kinds of learning that could not be efficiently managed or 
even possible without such tools (Ashburn \& Floden, 2006). Apart from being beneficial, technology might be fascinating especially when introduced for the first time in class. Kovalchick \& Dawson (2003) bring the example of their own students who showed a high level of interest and curiosity about technology when computers were first introduced. However, the use of technology in class might be challenging for both students and teachers; especially when it is introduced for the first time or even when resources are limited.

When new technology is introduced chances are that students and even teachers at some point might get confused. Kovalchick \& Dawson $(2003,68)$ bring the example of the Apple Classrooms of Tomorrow Project (ACOT) emphasizing that when computers were first introduced to ACOT classrooms, the technology added another layer of complexity to the classroom, a whole new set of things for already overworked and stressed teachers to learn and manage. Yet as the project continued, teachers found strategic ways to use the technology. Its use in instruction and learning changed as teachers themselves changed. Researchers described these changes in a model of instructional evolution that includes five stages: entry, adoption, adaptation, appropriation, and invention. In this model, instruction is first strengthened through the use of technology and then gradually replaced by far more dynamic learning experiences for students.

In an ideal 21 st century classroom technological devices would be available for both teachers and students. Depending on the location teachers may be faced with the challenge of teaching classes with limited resources, lack of technology. According to Arntsen (2018) teaching with limited resources can be both incredibly challenging and extremely educational.

In developing countries such as Albania teachers have to do without many classroom devices such as OHPs, video projectors, computers, laptops, and CD players. In the two schools where the project was implemented the pre-service teachers had no printer or photocopier available. This has been a great challenge to the pre-service teachers participating in the project. When possible the researchers tried to draw the pre-service teachers' attention to the questions: How can we do a lot with a little? How can we best use limited resources to support learning and familiarize little kids with the use of technology in language class? Acknowledging how challenging it is to teach in a low tech class, many researchers give advice on how to face this challenge. Barnett (2011) suggests that in order to best use limited technology resources to support learning and familiarize students with technology, the focus should be on how to be creative with the tools available, how to empower students by challenging them to teach one another, how to use students' personal devices and bring them in the classroom. Arntsen (2018) also focuses on the challenges of teaching in a limited resource environment and gives advice on how to surpass the obstacles. "When planning to teach in an area with limited resources consider taking some materials along to assist you during the transition period. Paper, printouts of materials you have used before, a laptop, an MP3 player, will help you in class and make the change more bearable. You will be able to show students pictures and videos using your laptop and conduct listening exercises using your music player" (Arntsen, 2018).

We'amHamdan (2017) also reports on how to adapt lessons in a low-tech environment. Teachers can't always rely on a steady internet connection, consistent electricity, or working technology. Low-tech classrooms feel limited in the 21st century. But what counts most is a teacher's subject knowledge and willingness to adapt lessons and technology use. We'amHamdan teaches English in Ramallah (Palestine), where technology often is not available in the classroom. Teachers and students have to think 'outside the box'. Sometimes when her technology-based lessons didn't go as she expected, but she had an alternative plan and surprisingly the lesson turned into a more thought- 
provoking one, where the students' imagination and creativity were tested. But this isn't always the case. When lacking technology in the classroom teachers have to improvise solutions using their personal technology sources and might lead to unexpected consequences.

Teacher educators are constantly trying to assist students master the basic technological tools they will need when they start teaching careers. But we are aware too of real-world limitations not all schools can keep up with the rapid changes of technology, especially those schools that are in highpoverty areas. Firstly, it requires financial resources many schools lack; secondly, if technology is used very rarely, it might be a source of distraction (Phillykids, 2017). Besides the government and community areas efforts helping the schools in high-poverty areas, our pre-service teachers attempted to be creative and use their personal technology sources, as often as they could to get the students used to the use and effectiveness of technology in the language classroom. The pre-service teachers in this study were encouraged to do so keeping in mind that by using ICT effectively, teachers could make learning more interesting and stimulating for students, while nurturing their creative and thinking skills.

\section{Methodology}

The research for this study started in October 2018 together with the implementation of the project. Two groups of six pre-service teachers started teaching English to underprivileged young learners every week, twice a week. Three university teachers served as mentors and facilitators for the pre-service teachers. This allowed the university teachers, the researchers in this case, to observe and record data in their journals. In total 54 classes were observed and qualitative data was collected. The researchers tried to focus on the impact the use of technology had on the third graders who have very limited technology access both at home and at school. The study of Hamilton (2015) served as a framework for this research focusing on three premises: when students use technology, they talk (premise 2), students learn when they actively participate (premise 3) and everything is easier with a partner (premise 7).

Simultaneously the pre-service teachers kept journals in which they wrote reflections of the classes they taught or observed. They were interviewed in January 2019 and qualitative data was gathered. This study is exploratory and the main focus of the interviews was to investigate the challenges that the pre-service teachers faced while using technology in class. The interviews also helped the researchers understand that apart from the challenges, pre-service teachers were also able to identify some advantages of teaching in a low tech environment.

The current study is limited in that the research is based on observations and interviews and the data is qualitative and mostly anecdotal. Yet, the results are significant as they identify several major challenges that pre-service teachers face while trying to use technology in class and they also try to shed light on the impact technology has had on learners who have limited access to technology and might be considered as a milestone for further research. 


\section{Results}

This research paper focuses on two major aspects of using technology in class. The first has to do with the impact the use of technology has on underprivileged young learners with very limited access to technology. The second aspect has to do with the challenges the pre-service teachers faced while trying to use technology in class.

\subsection{The impact the use of technology has on underprivileged third graders.}

When students use technology, they talk (Hamilton, 2015)

During the observations, the researchers focused on the connection between the use of technology and the amount of time third graders spent talking. The technology devices that were used as educational tools during the project were: laptop, $\mathrm{CD}$ rom, video projector, smart phones, speakers, etc. The activities included mostly: listening for main ideas, watching cartoons and videos, making phone calls, etc. In total 54 classes were observed and the results of the observations indicate that third graders show a higher level of enthusiasm and readiness to speak when activities were based on the use of technology. The researchers focused on two aspects of teaching: Teacher Talking Time (TTT) and Student Talking Time (STT). What resulted from the observations was that there was more STT than TTT in the classes in which technology was integrated. The data collected by the observations was emphasized even by the regular feedback received by third graders at the end of the classes.

The affective filter seemed to be low and almost all the students engaged in speaking activities; even the students with special needs tended to join. This was not unexpected. Children are curious by nature and the use of technology in the classroom makes them even more curious and interested. Using $\mathrm{CD}$ rom in class to practice listening activities; fill in the gaps, cloze, listen for details etc. made third graders to talk more during the learning process. We believe that the use of $\mathrm{CD}$ rom would have been more beneficial if the third graders would have had the possibility to use at home the CDs they got together with the textbooks. All the third graders had a CD which could have been used at home, but as already mentioned the majority of these students do not have the technology devices at home.

The use of technology encourages active participation and collaboration among young learners (Hamilton, 2015)

Most of the activities practiced during the project, which included the use of technology, encouraged interaction among students through pair work and group work. Pre-service teachers in their interviews mentioned that they noticed an increased level of curiosity on some of the technological devices by some of the third graders, and an increased level of motivation to participate in hands-on activities. This may be due to the fact that some of the devices were not very familiar to the third graders, who, as said above, have very limited access to technology. Associating the technology with fun activities is another incentive for the young learners to participate more actively in activities using technology.

Using smart phones to practice a phone conversation, was a fun activity that third graders enjoyed very much. When used, it was successful in teaching third graders greetings and introducing themselves. According to the responses of the pre-service teachers' interviews, using smart phones as educational tools is something interesting, fun and enjoyable for the third graders. 
"Observing Lea and Erla pretending to have a telephone conversation in English was impressive. They seemed so engaged in the conversation and tried to improvise by including in the conversation questions which were not part of the script. They were excited and this made other students willing to practice the same activity" (Arlinda- pre-service teacher)

The pre-service teachers also added that the use of these educational tools motivate collaboration among young learners. One of the activities included watching a short video. The preservice teachers discussed which video was more appropriate for the third graders and decided what activities they should practice and how they should proceed. The aim of the activity was to practice speaking. In groups of four third graders had to watch the video and then answer five short questions prepared by the pre-service teachers. One pre-service teacher was responsible per one group of four third graders and his/her assignment was to encourage third graders to talk. The pre-service teachers reported some feedback of the third graders as follows.

"I love the activity when we had to watch cartoons and then in groups we had to answer the questions. My friends and I had so much fun. It was cool" (Arlindi, 8 years old).

"In my group we asked the teacher to watch the videos again in the next class. We talked about the cartoons and answered the questions. My friend Sara wanted to answer all the questions but the teacher said we should all talk about the video even though we don't know the answers very well" (Frenkli, 9 years old)

"I am not very good at speaking in English, but I like the video and when my friends wanted to identify the colors of the character in the video I remembered them and told them to my friends. I am so happy for this" (Ismaili, 8).

\subsection{The challenges of the pre-service teachers}

One of the main challenges that our pre-service teachers face is that sometimes they might not own or have access to the technology devices as many K12 schools do not provide them. During their graduate studies students take the course "Teaching English through Old and New Media" during which they learn how to use media and technology in teaching. Although they were prepared to integrate technology in teaching not having access to the technology devices or having very limited access was challenging for them. The pre-service teachers had to bring their laptops, the speakers, and the video projector to class in order to facilitate learning. They often had to improvise and be creative. In one of the classes during which the preservice teachers had to use the projector, the blackboard made it impossible to watch the video, so the pre-service teachers had to bring a white sheet from home, hang it on the wall and make it possible for the third graders to watch the video. In another case they had to learn the songs; the lyrics and the melody in case something went wrong with the laptop or the speaker. This resulted in pre-service teachers learning to improvise and be resourceful.

Another challenge our pre-service teachers faced is that often there is little connection between what is being taught pedagogically at the university and what they experience during their teacher observations they do at schools. For instance, the students have studied and practiced during the microteaching sessions how to use movies and videos in class. Although a good start, the simulations only give students a broad idea on how to practice the activities and when they had to use a video during the lesson they needed the support of the university teachers. One of the pre-service teachers said: 
"It seemed easier when I gave the presentation using videos in our microteaching session. It was helpful as it taught me how to plan and deliver the activity, but now that I have to practice it in a real class, with real students and somehow under pressure I feel a bit insecure. I wish I had observed more examples of using videos in the class by my mentor teachers during the teaching practice. It might also be the lack of experience" (Anxhela)

Sometimes the pre-service teachers find it difficult to use the technology in class in the best possible way. This means that even though they might have access to some technology in class, it is challenging for them to use it efficiently. This is due to two important factors. Firstly, is the lack of experience. We are all aware of the importance of professional development. Being at the first or second year of their studies, our pre-service teachers have had no experience in teaching whatsoever. Secondly, as mentioned above our pre-service teachers have unfortunately been able to observe classes in which the use of technology is not included enough. Although there are good examples by professional teachers who include the use of technology, it is not easy for the preservice teachers to adapt them in their own teaching. One of the pre-service teachers said:

"I entered the classroom full of confidence. I had planned the activities in details, I had discussed them with my friends and the mentors. I imagined various scenarios and pictured similar activities that I had observed during the teaching practice. Unfortunately, things did not go as planned. The internet connection was poor and I was unable to show the video to the students. I probably should have downloaded the video and the pictures" (Emine).

Apart from the many challenges that the pre-service teachers faced, it is necessary to emphasize that this situation had its own advantages. At the beginning the pre-service teachers were a bit resistant to integrate technology in class. The reasons were various but the university teachers who supervised them encouraged and mentored them in every step. During the weekly preparatory meeting the pre-service teachers had to discuss the lesson plan and to decide what technology devices they would use and how, who would bring each device and what would they do in case something would go wrong: the devices not working properly, lack of electricity etc. During the interviews though the pre-service teachers mentioned three main advantages which were also reflected on the observations of the researchers. First, the pre-service teachers declared that they felt they become more creative and flexible. Second, they became more organized. Third, they were more open to experiment, to accept the challenge and to find alternative ways to succeed in teaching with limited technology resources.

\section{Discussion}

There are numerous studies which focus on the benefits of using technology in class to facilitate learning, including language learning. There are various recommendations for both in-service and pre-service teachers on how to best use technology (Barnett, 2016; We'amHamdan 2017). Other researchers claim that although technology is very important in class it doesn't necessarily create meaningful change in learning instruction (Flanagan 2016). Kovalchick \& Dawson (2003) suggest that at the beginning or if used rarely, technology might also be a source of distraction. In a recent study Davis \& Currie (2019) claim that in fact technology has no impact on teaching and learning and they suggest that schools should invest in creating a cadre of well-trained coaches who know how to work with individuals and teams of teachers to help them thoughtfully and meaningfully integrate technology into their classes in ways that feel sustainable. 
We agree that as various studies emphasize, using different forms of technology in class has become a necessity if we today's educators are going to effectively prepare students and train future teachers to participate in global community. Hence the authors of this paper have encouraged the preservice teachers to use technology in class. And when they do so, they also have in mind the impact the use of technology has on the third graders who are part of this project. From our observations and from the pre-service teachers' opinions we could identify an increased level of enthusiasm of third graders to actively participate in activities that integrate technology. Third graders tend to collaborate more and students talking time tends to be longer when technology is integrated.

Many schools lack technology devices; in the best of cases there in one projector for approximately 30 teachers. In many cases teachers have to provide the devices themselves or to rely on parents, community or organizations. Because of this technology unfriendly situation, some in-service teachers tend not include technology in class as much as needed. This means that pre-service teachers who observe these in-service teachers during the teaching practice do not have many possibilities to observe how various activities which imply the use of technology are put in practice. This in fact is not encouraging for our pre-service teachers considering that novice teachers tend to teach the way they were taught, not the way they are told to teach.

At the beginning some lack of confidence was noticed on the part of pre-service teachers, but with the passing of the time, alongside with the activities at university, they have become more confident and have shown increased creativity in their classes, especially concerning the use of technology. Although the access to technology has been very limited, especially in the two schools where the project was implemented, and the students faced challenges they were motivated to experiment and succeed in making teaching and learning English more engaging and interactive.

\section{Conclusions}

This paper focused on two aspects of technology and teaching: the impact of using technology in a limited access to technology environment and the challenges that the pre-service teachers faced while teaching in a limited access to technology environment. The importance of this paper is that while other research in Albania focuses on the benefits of using technology in class, this exploratory study focuses on the challenges and encourages pre-service and in-service teachers to find ways to incorporate technology in class even if access to technology is very limited.

There were several challenges of using technology as a teaching tool encountered by the preservice teachers such as: not being able to observe many classes where activities included the use of technology, the lack of experience and access to technology made it difficult sometimes to practice what they learned at the university. The pre-service teachers had to rely on their own devices and to bring them in the classroom to use. Apart from the challenges there was a positive aspect in this situation. The limited access to technology and the necessity to integrate it while teaching helped preservice teachers become more creative and flexible, more organized and determined to accept the challenges. Considering the impact the use of technology has on teaching in a limited technology access class of third graders, the pre-service teachers were encouraged to use technology as often as they could. When technology was integrated in class the pre-service teachers and the researchers observed: increased collaboration among third graders, the affective filter of the third graders seemed to be lower, and third graders became more curious and willing to participate in all the activities. 


\section{References}

Arnsten, T. (2017). Teaching With Limited Resources: Tough Challenge Or Useful Experience. Retrieved from: https://busyteacher.org/4816-teaching-with-limited-resources-toughchallenge.html Retrieved March 2019

Ashburn, A. E \& Floden, E. R. (2006). Meaningful Learning Using Technology: What Educators Need to Know and Do. Teachers College Press, New York

Barnett, J. (2011). High-Tech Teaching in a Low-Tech Classroom. Retrieved from: https://www.edweek.org/tm/articles/2011/08/10/barnett_hightechteaching.html Retrieved, February, 2019

Davis, E \& Currie, B (2019). Technology has no impact on teaching and learning. Retrieved

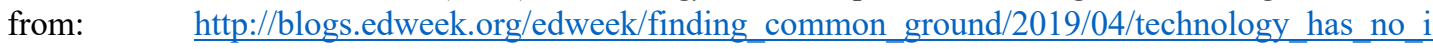
Impact_on_teaching_and_learning.html

Hamilton, B. (2015). Integrating Technology in the Classroom: Tools to Meet the Need of Every Student. ISTE, USA

Harold, B. (2017). How schools are tackling tech training for teachers, "passive" vs. "active" use of digital tools. Retrieved from: ew.edweek.org/fx/save/dbindex.php?book_id=_NXT...pdf $=1$

Kovalchick, A. and Dawson, K. (2003). Education and Technology, and Encyclopedia. Publisher ABC- CLIO, California

Klopfer, E., Osterweil, S., Groff, J. and Haas, J. (2009). Using the technology of today, in the classroom today. The Instructional Power of digital games, social networking, simulations and how teachers can leverage them. The Education Arcade, Massachusetts Institute of Technology https://education.mit.edu/wp-content/uploads/2018/10/GamesSimsSocNets_EdArcade.pdf

Kwok-Wing Lai (2011). Digital technology and the culture of teaching and learning in higher education. Australasian Journal of Educational Technology (Special issue, 8), 1263-1275)

Peters, L. (2009). Global Education. Using technology to bring the world to your students. International Society for Technology in Education EUGENE, OREGON • WASHINGTON, D

Philadelphia Children's Foundation (2018). Lack of Technology, from http://phillykids.org/about-p-c f/lack-of-technology/, Retrieved, March, 2019

Qoitassi, M. K. and Sharif, M. J. R (2015). The usability of classroom technologies in English language teaching and learning (ELT\&ELL). International Journal ANGLISTICUM, Vol 4, Number 9-10

Wenglinsky, H. (2005). Using Technology Wisely: The Keys To Success In Schools. Teachers College Press, New York

We'amHamdan (2017). Tips for teaching in a low-tech classroom https://www.britishcouncil.org/voices-magazine/tips-teaching-low-tech-classroom 